\title{
Influences of Athletic Footwear on Ground Reaction Forces During A Sidestep Cutting Maneuver on Artificial Turf
}

Jacob R. Gdovin ${ }^{1 *}$, Charles C. Williams ${ }^{2,3}$, Samuel J. Wilson ${ }^{3,4}$, Vanessa L. Cazas-Moreno ${ }^{5}$, Lauren A. Luginsland ${ }^{3}$, Charles R. Allen ${ }^{6}$, Harish Chander ${ }^{7}$, Chip Wade ${ }^{8}$, John C. Garner III ${ }^{9}$

${ }^{1}$ Department of Kinesiology; Missouri State University 901 S. National Ave., Springfield, MO 65897 USA

${ }^{2}$ Department of of Exercise Science; LaGrange College , 601 Broad Street, LaGrange, GA 30240 USA

${ }^{3}$ Department of Health, Exercise Science and Recreation Management; The University of Mississippi 215 Turner Center, P.O. Box 1848, University, MS 38677 USA

${ }^{4}$ Department of Health Sciences and Kinesiology; Georgia Southern University P.O. Box 8076, Statesboro, GA 30460 USA

${ }^{5}$ Department of Human Performance and Sport Sciences; Tennessee State University 3500 John A. Merritt Blvd., Nashville, TN 37209 USA

${ }^{6}$ Department of Exercise Science; Florida Southern College 111 Lake Hollingsworth Dr., Lakeland, FL 33801 USA

${ }^{7}$ Neuromechanics Laboratory, Department of Kinesiology; Mississippi State University PO Box 6186, Mississippi State, MS 39762 USA

${ }^{8}$ Department of Industrial and Systems Engineering; Auburn University Auburn, AL 36849 USA

${ }^{9}$ Department of Kinesiology and Health Promotion; Troy University 112G Wright Hall, Troy, AL 36082 USA

Corresponding Author: Jacob R. Gdovin, E-mail: JacobGdovin@missouristate.edu

\section{ARTICLE INFO}

Article history

Received: February 4, 2018

Accepted: April 20, 2018

Published: April 30, 2018

Volume: 6 Issue: 2

Conflicts of interest: None

Funding: None

\begin{abstract}
Background: Recreational athletes can select their desired footwear based on personal preferences of shoe properties such as comfort and weight. Commonly worn running shoes and cleated footwear with similar stud geometry and distribution are worn when performing sport-specific tasks such as a side-step cutting maneuver (SCM) in soccer and American football (hereafter, referred to as football). The effects of such footwear on injury mechanics have been documented with less being known regarding their effect on performance. Objective: The purpose of this study was to examine performance differences including peak ground reaction forces (pGRF), time-topeak ground reaction forces (tpGRF) and the rate of force development (RFD) between football cleats $(\mathrm{FB})$, soccer cleats (SOC), and traditional running sneakers (RUN) during the braking and propulsive phases of a SCM. Methodology: Eleven recreationally active males who participated in football and/or soccer-related activities at the time of testing completed the study. A 1 x 3 [1 Condition (SCM) x 3 Footwear (RUN, FB, SOC)] repeated measures ANOVA was utilized to analyze the aforementioned variables. Results: There were no significant differences $(p>0.05)$ between footwear conditions when comparing pGRF, tpGRF, or RFD in either the braking or propulsive phases. Conclusion: The results suggest that the studded and non-studded footwear allowed athletes to generate similar forces over a given time frame when performing a SCM.
\end{abstract}

Key words: Shoes, Football, Soccer, Athletes, Running

\section{INTRODUCTION}

The shoe-surface interface defines how an athlete's footwear interacts with the underlying playing surface assisting with the implementation of sport-specific movements such as sprinting, cutting, and stopping. The mechanism allowing this interaction lies in the understanding of vertical and horizontal resistive forces. Vertical resistive forces determine a cleats ability to penetrate a playing surface (Driscoll, Kelley, Kirk, Koerger, \& Haake, 2015) which can be influenced by surface hardness as well as cleat design (i.e., stud geometry) (Clarke \& Carré, 2010). Surface hardness is the ability of a surface to absorb impact energy upon it being struck by an object (SportsTurf Managers Associations [STMA], 2008). When the energy is created by an athlete's foot, the reactionary force can be referred to as a ground reaction force (GRF). Traction, which comprises the horizontal resistive force and can be referred to as grip-ability, describes how cleated footwear resists the motion of the body relative to the surface (McNitt, Middour, \& Waddington, 1997).

Cleats are frequently worn in soccer and football as they play a vital role in an athlete's performance during these sports. Approximately 265 million athletes participate in soccer globally (Fédération Internationale de Football Association [FIFA], 2007); it is accepted to be the most popular sport in the world. Football also maintains its popularity 
with over one million reported male high school football athletes in the United States (National Federation of State High School Associations, 2017). The increase in participation within both sports has provided shoe manufacturers incentive to develop various cleat designs exclusively for tasks related to a specific sport and position in attempt to improve performance. Cleat differences vary between models and manufacturers with stud geometry (i.e. cylindrical, conical, prismatic, and bladed) and distribution (i.e. turf, artificial grass, hard ground, firm ground, and soft ground) being the differentiating variables (Sterzing, 2016). However, recreational athletes can select their own footwear and are not limited to footwear specific to their sport.

Cleated footwear is designed to assist with foot and ankle stabilization while simultaneously improving an individuals ability to perform sport-specific movements, such as a side-step cutting maneuver (SCM), by allowing for a strong push-off in any direction without slipping (Sterzing, 2016). The SCM is utilized in both sports and is described as a highspeed evasive movement with a sudden change in direction, often at an angle of approximately $45^{\circ}$ relative to the running direction (Havens \& Siward, 2015; McLean, Neal, Myers, \& Walters, 1999; Vanrenterghem, Venables, Pataky, \& Robinson, 2012). Within the SCM, two phases exist which enable the change in direction to occur: the braking and propulsion phases. The braking phase occurs from the instance of foot contact until the pGRF and is responsible for assisting with the body's negative acceleration to prepare for a rapid change in direction. The subsequent propulsion phase allows the athlete to generate velocity in the newly intended direction, which occurs in the time between the braking pGRF and foot toe-off. Numerous variables have been associated with effecting lower extremity mechanics and performance during a SCM such as footwear design, cleat arrangements, shoe-surface interaction (Kent, Forman, Lessley, \& Crandall, 2015b), cutting angle (Havens \& Sigward, 2015), and approach speed (Vanrenterghem et al. 2012). Previous literature has shown that prolonged activity may also effect performance due to the decrease in the neuromuscular response and/or control as the duration of playing time may increase (McGovern et al., 2015).

Injuries within both sports arise due to several factors with a common mechanism stemming from the increasing size, speed, and strength of the athletes. This may indirectly alter the traction developed from cutting with a foot planted while the upper body rotates. Among male high school athletes, game and practice injury rates were highest for football and soccer to the foot and ankle, representing $15.9 \%$ and $33.5 \%$ of all reported injuries, respectively (Powell \& Barber-Foss, 1999). In 2005, the rate of lower limb injuries among high school male athletes was the highest in football while soccer had the highest rate among females with common injuries including sprains $(50 \%)$, strains $(17 \%)$, contusions (12\%), and fractures (5\%) (Fernandez, Yard, Comstock, 2007). Within the sport of soccer, $42 \%$ of all injuries are due to intrinsic player-controlled factors such as muscle weakness, while $24 \%$ of injuries were due to poor playing surfaces combined with "inferior shoes" (Nigg,
1989). These injuries can arise due to intrinsic risk factors, such as lack of experience, position within the sport, biological age, and joint flexibility combined with extrinsic factors such as shoe-surface interaction, field conditions, and equipment (Dvorak \& Junge, 2000; Iacovelli et al., 2013).

While previous research has examined how a SCM and cleated footwear alters injury possibilities, the effect they have on performance variables have not been as widely analyzed, with the exception of a few studies (Brock et al., 2014; Durá, Hoyos, Martinez, \& Lozano, 1999; McGhie \& Ettema, 2008; Meijer, Dethmers, Savelberg, Willems, \& Wijers, 2006; Queen et al. 2008). The GRFs exerted against a cleats sole is vital for understanding how quickly and forcefully an athlete can run and change direction. Previous research on artificial turf analyzing GRFs is scarce with (Saggini \& Vecchiet, 1994) evaluating soccer footwear on natural turf at a speed of $2.8 \mathrm{~m} \mathrm{~s}^{-1}$. However, the latter study did not report footwear characteristics, data filtering techniques, surface thickness, nor how the surface was attached to the force platforms. Similarly, it has also been found that studded cleats produce significantly larger peak impact values compared to bladed cleats and turf shoes during sport-specific movements (McGhie \& Ettema, 2013), while GRFs were found to be equal in magnitude on different types of turf with the same fourteen studded cleat (Verhelst et al., 2008). Ultimately, past studies have failed to investigate the GRFs produced while wearing cleated footwear with similar stud configurations designed for different sports. Therefore, the purpose of this study was to examine the performance differences in mediolateral and vertical peak GRF (pGRF), time-to-peak GRF (tpGRF), and the rate of force development (RFD) in football cleats (FB), soccer cleats (SOC), and traditional running shoes (RUN) during the braking and propulsive phases of a SCM on artificial turf. It was hypothesized that the FB cleats would produce larger pGRF, tpGRF, and RFD in the mediolateral direction due to the position of bladed cleats at the medio-lateral surface of the outsole while SOC would produce larger values in the vertical direction. Athletes had previously perceived bladed cleats to increase the interaction between the footwear and the surface during the SCM due to a larger contact area (Sterzing, 2016).

\section{METHODOLOGY}

\section{Participants}

An a-priori analysis using data from the male subjects in Butler et al. (2014) estimated twelve participants were needed based off the following input parameters: $\beta=.20, \alpha=.05$, effect size $=.38$, and non-sphericity correction of 1.0 while including 9 different measures of 3 groups with an estimated correlation of 0.3 across the measurements. Twelve participants were recruited and completed the study; however, eleven healthy male participants (Age: $21.8 \pm 1.5$ years; Height: $1.81 \pm 0.05 \mathrm{~m}$; Weight: $87.8 \pm 14.4 \mathrm{~kg}$ ) were used for analysis due to equipment malfunction. All participants were actively engaged in football and/or soccer-related activities such as practices, drills, or games at a competitive recreational level while wearing cleats for a minimum of 1 hour per week within the last year. All participants were Exercise 
Science students recruited from various classes. Participants were excluded if they had a history of any lower extremity musculoskeletal injury within the past six months or a lower extremity reconstructive surgery within the past three years. The study was approved by the Institutional Review Board (IRB) at The University of Mississippi. Prior to collection, participants were screened for musculoskeletal, orthopedic, and cardiovascular anomalies using the Physical Activity Readiness Questionnaire (PAR-Q) by the American College of Sports Medicine (2013).

\section{Procedures}

Participants were tested in all three types of footwear (FB, SOC, RUN) with the order determined by a counterbalanced design. All participants completed a dynamic warm-up (Cazás-Moreno et al., 2015) with additional self-directed stretching of the trunk and lower extermity, if desired. Upon conclusion of the warm-up and prior to testing in each footwear, participants were allowed as many warmup repetitions of the SCM as necessary. This allowed the participants to adapt to the shoe-surface interaction in order to mimic game-like speed and technique. Participants began in an upright standing start position and were instructed to run towards the force platform at full speed from a distance of $4.57 \mathrm{~m}$ away to mimic the initial start in a pro-agility drill. An orange cone was placed on the opposite side of the force platform to indicate the location in which they were supposed to plant their foot and perform the SCM. Within each type of footwear, participants were instructed to complete a SCM on their dominant (kicking) leg. The dominant foot made contact with the force platform while they cut and pushedoff in the opposite direction (i.e., right leg dominance: right foot contacts the force platform while participants cut to the left). Similar to previous studies (Smith, Dyson, \& Janaway, 2004; Queen et al., 2008), the testing protocol had participants perform between 5-10 SCM in all three footwear conditions until three successful trials occurred. If numerous trials were deemed successful, the first three were used for analysis. A successful trial was defined as when the participant's entire foot made contact with the force platform. To avoid fatigue, a 30-second rest between SCM trials was allotted as well as a 10-minute break between shoe conditions where participants were instructed to sit down without shoes to act as a washout period.

\section{Instrumentation}

A 0.4m x 0.4m AMTI OR6-6 (AMTI, Inc., Watertown, MA, USA) force platform embedded into the floor captured GRFs during foot contact at $1000 \mathrm{~Hz}$. Data were filtered using a fourth-order Butterworth with a cutoff frequency set at $15 \mathrm{~Hz}$. Vinyl tile covered the force platform matching the rest of the capture volume to reduce targeting. Similar to previous studies (Bennett, Brock, Brosnan, Sorochan, \& Zhang, 2015; Brock et al., 2014; Durá, Hoyos, Martinez, \& Lozano, 1999), a $1.83 \mathrm{~m} \times 8.54 \mathrm{~m}$ strip of synthetic turf (AstroTurf, Dalton, GA) with a Styrene-Butadiene Rubber (SBR) infill was securely attached to the force platform and runway via Industrial Strength Extreme VELCRO ${ }^{\circledR}$ (Manchester, NH, USA) (Figure 1). Another $1.83 \mathrm{~m} \times 8.54 \mathrm{~m}$ strip of synthetic turf, comprised of the same material, was cut into two $1.83 \mathrm{~m} \mathrm{x}$ $4.27 \mathrm{~m}$ strips and was placed parallel to the primary runway.

\section{Footwear}

The procedures carried out by each participant were completed in a traditional runnning shoe [Nike Dart], soccer cleat [Nike Tiempo Rio II FG], and football cleat [Nike Alpha Strike 2 TD] (Figure 2). Running shoes acted as a control between the cleated footwear conditions while also imitating recreational athletes not utilizing cleated footwear during competition. The footwear for this study was selected based on the popularity of use with local Division-I National Collegiate Athletic Association (NCAA) athletes. Footwear characteristics are listed in Table 1 with the average shoe size worn by the participants being eleven (U.S. sizing). All cleats utilized were new at the time of testing and were properly fitted and laced by the researchers to minimize variability in lacing techniques. No mechanical data were available on footwear differences.

\section{Data Analysis}

The first three successful trials collected were averaged to calculate pGRF, tpGRF, and RFD for each participant in all three footwear conditions. All variables of interest were calculated in both the braking and propulsion phases of the SCM in the mediolateral and vertical directions. pGRF was the largest magnitude along the mediolateral and vertical axes. tpGRF depicts the total length of time it takes a participant to reach their peak magnitude. This variable during the braking phase

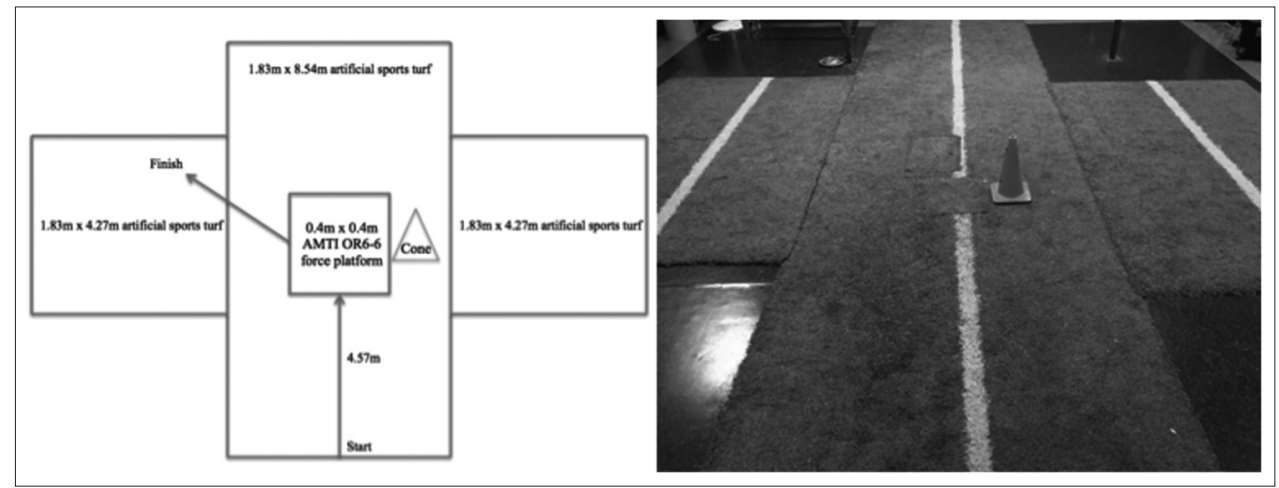

Figure 1. Experimental Setup 

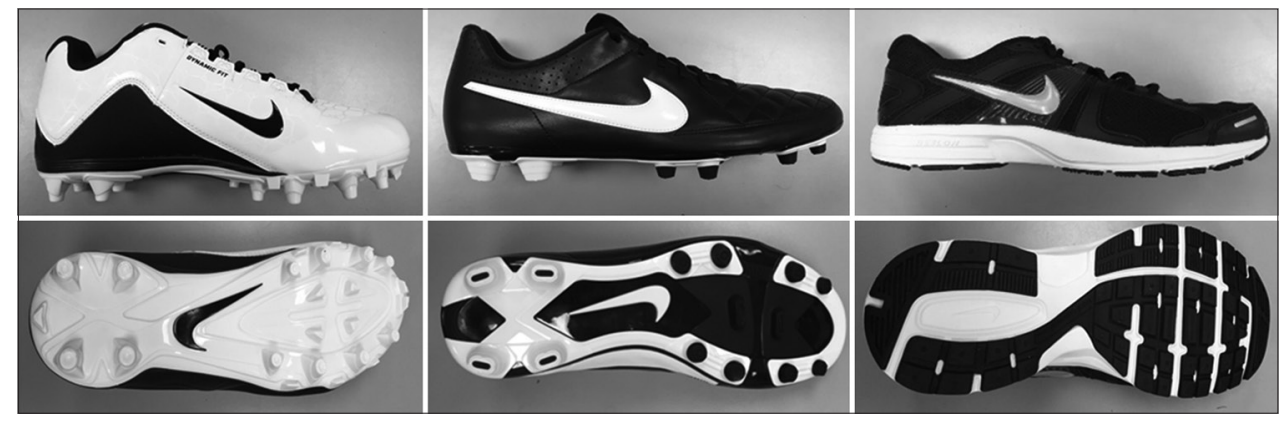

Figure 2. Footwear: Nike Alpha Strike 2 TD Football Cleat (FB); Nike Tiempo Rio II FG Soccer Cleat (SOC); Nike Dart Running Shoe (RUN)

Table 1. Footwear characteristics

\begin{tabular}{lccc}
\hline & Football cleat (FB) & Soccer cleat (SOC) & Running shoe (RUN) \\
\hline Mass (kg) & 0.318 & 0.213 & 0.289 \\
Total \# of studs & 12 & 12 & $\mathrm{n} / \mathrm{a}$ \\
Mid-forefoot stud height $(\mathrm{cm})$ & 1.6 & 1.7 & $\mathrm{n} / \mathrm{a}$ \\
Medial/lateral forefoot stud height $(\mathrm{cm})$ & 2.1 & 2 & $\mathrm{n} / \mathrm{a}$ \\
Rearfoot stud height $(\mathrm{cm})$ & 2.1 & 2.4 & $\mathrm{n} / \mathrm{a}$ \\
\hline
\end{tabular}

looked at the time from initial foot contact (defined as when force increased $1 \mathrm{~N}$ above body weight) to peak brake, while the propulsion phase was estimated from the time it took from the peak brake time to the peak propulsion time. RFD was determined by the amount of force produced over the change in time within each direction and phase of the SCM (Cazás-Moreno et al., 2015; Haff, Ruben, Lider, Twine, \& Cormie, 2015). All kinetic data were normalized to each participant's body weight $(\mathrm{N})$ to allow for comparative analysis.

\section{Statistical Analysis}

A $1 \times 3$ [1 Condition (SCM) x 3 Footwear (RUN, FB, SOC)] repeated-measures analysis of variance (ANOVA) with an alpha level set at 0.05 was used to measure the effects of the three types of footwear on pGRF, tpGRF, and RFD. If a significant main effect of footwear was found, a Bonferroni posthoc adjustment was used. Intra-class correlation coefficients (ICC) were then calculated as a reliability measure due to the presence of artificial turf on the force platforms. All analyses were conducted using the SPSS 21 statistical software package (IBM SPSS ${ }^{\circledR}$ Statistics V21.0, Armonk, NY, USA).

\section{RESULTS}

There were no statistically significant differences $(p>0.05)$ between footwear when comparing mediolateral and vertical pGRF, tpGRF, or RFD in either the braking or propulsive phases of a SCM (Table 2). However, significant ICCs were present for $\mathrm{pGRF}$ in the mediolateral and vertical directions during the braking and propulsion phase as well as RFD in both directions during the braking phase (Table 3).

\section{DISCUSSION}

The purpose of this study was to examine the performance differences in mediolateral and vertical pGRF, tpGRF, and
RFD in FB cleats, SOC cleats, and running shoes during the braking and propulsive phases of a SCM on artificial turf. It was hypothesized that the FB cleat would produce larger pGRF, tpGRF, and RFD in the mediolateral direction while the SOC cleat would produce larger values in the vertical direction. The results from this study indicate that there were no statistical differences in any of the kinetic variables of interest between footwear in both the braking and propulsion phases of a SCM. This suggests that footwear, with or without studs, allowed athletes to generate comparable GRFs in a similar time frame. More specifically, football and soccer cleats with similar stud characteristics allow individuals to generate similar forces over a given time frame when performing a SCM. Although no significant differences were present, SOC cleats allowed participants to produce greater forces in the braking and propulsion phase within the mediolateral and vertical directions, respectively. Similarly, SOC cleats had allowed participants to generate faster tpGRF in both directions and phases except for the propulsion phase in the mediolateral direction. This may be explained by the fact the SOC cleat had longer mid-forefoot studs and a lighter mass compared to the FB cleat. Footwear that is lighter with longer studs may provide a greater depth of penetration allowing for a greater shoe-surface interaction; therefore, eliciting greater force production in a shorter time period.

In regard to surfaces, previous literature has shown that artificial turf generates greater peak horizontal forces in translational movements, peak torques in rotation movements, and peak vertical forces in translation/drop tests relative to natural turf (Kent, Forman, Crandall, \& Lessley, 2015a). However, since artificial turf has been shown not to tear or divot, the maximum force measured is limited to the maximum force produced by an individual (Kent et al., 2015a). This indicates that varying results may be due to participants' lower extremity strength and experience performing the SCM. Similarly, the exact depth of the infill 
Table 2. Kinetic variables of a SCM

\begin{tabular}{|c|c|c|c|c|c|}
\hline Variable (units) & $\begin{array}{c}\text { Football } \\
\text { cleat }(\mathrm{FB})\end{array}$ & $\begin{array}{c}\text { Soccer } \\
\text { cleat }(\mathrm{SOC})\end{array}$ & $\begin{array}{c}\text { Running } \\
\text { shoe (RUN) }\end{array}$ & F-value & $\eta_{\mathrm{p}}^{2}$ \\
\hline \multicolumn{6}{|c|}{ Mediolateral braking } \\
\hline pGRF (BW) & $1.55(0.03)$ & $1.68(0.24)$ & $1.55(0.41)$ & $(\mathrm{F}(1.447,14.467)=1.374, \mathrm{P}=0.275)$ & 0.121 \\
\hline tpGRF (s) & $0.237(0.052)$ & $0.217(0.019)$ & $0.214(0.008)$ & $(\mathrm{F}(1.166,11.661)=1.557, \mathrm{P}=0.241)$ & 0.135 \\
\hline $\mathrm{RFD}(\mathrm{BW} / \mathrm{s})$ & $6.81(1.88)$ & $7.74(0.98)$ & $7.26(1.93)$ & $(\mathrm{F}(1.393,13.932)=1.640, \mathrm{P}=0.228)$ & 0.141 \\
\hline \multicolumn{6}{|l|}{ Vertical braking } \\
\hline pGRF (BW) & $3.86(0.7)$ & $3.82(0.7)$ & $3.5(1.3)$ & $(\mathrm{F}(1.368,13.684)=1.439, \mathrm{P}=0.262)$ & 0.126 \\
\hline $\operatorname{tpGRF}(\mathrm{s})$ & $0.249(0.052)$ & $0.225(0.019)$ & $0.224(0.006)$ & $(\mathrm{F}(1.210,12.096)=2.268, \mathrm{P}=0.156)$ & 0.185 \\
\hline $\mathrm{RFD}(\mathrm{BW} / \mathrm{s})$ & $16.04(4.25)$ & $17.09(3.43)$ & $15.75(6.07)$ & $(\mathrm{F}(1.734,17.340)=0.682, \mathrm{P}=0.499)$ & 0.064 \\
\hline \multicolumn{6}{|c|}{ Mediolateral propulsion } \\
\hline pGRF (BW) & $1.66(0.24)$ & $1.65(0.25)$ & $1.57(0.28)$ & $(\mathrm{F}(1.464,14.638)=1.225, \mathrm{P}=0.308)$ & 0.109 \\
\hline $\operatorname{tpGRF}(\mathrm{s})$ & $0.025(0.012)$ & $0.033(0.024)$ & $0.037(0.012)$ & $(\mathrm{F}(1.657,16.572)=1.148, \mathrm{P}=0.331)$ & 0.103 \\
\hline $\mathrm{RFD}(\mathrm{BW} / \mathrm{s})$ & $78.97(48.7)$ & $59.62(40.66)$ & $46.2(12.86)$ & $(\mathrm{F}(1.584,12.673)=1.558, \mathrm{P}=0.246)$ & 0.163 \\
\hline \multicolumn{6}{|l|}{ Vertical propulsion } \\
\hline pGRF (BW) & $2.45(0.42)$ & $2.52(0.45)$ & $2.57(0.81)$ & $(\mathrm{F}(1.903,19.026)=1.198, \mathrm{P}=0.198)$ & 0.019 \\
\hline $\operatorname{tpGRF}(\mathrm{s})$ & $0.078(0.024)$ & $0.065(0.035)$ & $0.066(0.03)$ & $(\mathrm{F}(1.838,18.380)=0.820, \mathrm{P}=0.446)$ & 0.076 \\
\hline RFD (BW/s) & $31.15(10.51)$ & $54.49(48.83)$ & $36.62(19.52)$ & $(\mathrm{F}(1.309,11.783)=1.476, \mathrm{P}=0.258)$ & 0.141 \\
\hline
\end{tabular}

Data are expressed as means ( $\pm \mathrm{SD})$. Variables: peak ground reaction force (pGRF); time-to-peak ground reaction force (tpGRF); rate of force development (RFD). Units: Body weight (BW), Seconds (s). No significant differences were found between footwear ( $p>0.05)$.

Table 3. Intraclass correlation coefficients (ICC)

\begin{tabular}{|c|c|c|c|c|}
\hline \multirow[t]{2}{*}{ Variable (units) } & \multirow[t]{2}{*}{ ICC } & \multirow[t]{2}{*}{ p-value } & \multicolumn{2}{|c|}{ Confidence intervals } \\
\hline & & & Lower bound & Upper bound \\
\hline \multicolumn{5}{|c|}{ Mediolateral braking } \\
\hline pGRF (BW) & $0.801^{*}$ & 0.001 & 0.448 & 0.942 \\
\hline tpGRF (s) & -0.063 & 0.519 & -1.948 & 0.689 \\
\hline RFD (BW/s) & $0.727 *$ & 0.007 & 0.243 & 0.920 \\
\hline \multicolumn{5}{|l|}{ Vertical braking } \\
\hline pGRF (BW) & $0.865^{*}$ & $<0.001$ & 0.626 & 0.961 \\
\hline tpGRF (s) & 0.227 & 0.298 & -1.143 & 0.774 \\
\hline RFD (BW/s) & $0.841^{*}$ & $<0.001$ & 0.559 & 0.954 \\
\hline \multicolumn{5}{|c|}{ Mediolateral propulsion } \\
\hline pGRF (BW) & $0.888^{*}$ & $<0.001$ & 0.689 & 0.967 \\
\hline tpGRF (s) & -0.453 & 0.724 & -3.031 & 0.575 \\
\hline RFD (BW/s) & -0.484 & 0.708 & -3.637 & 0.636 \\
\hline \multicolumn{5}{|l|}{ Vertical propulsion } \\
\hline pGRF (BW) & $0.722 *$ & 0.007 & 0.228 & 0.919 \\
\hline tpGRF (s) & 0.408 & 0.153 & -0.642 & 0.827 \\
\hline RFD (BW/s) & -0.177 & 0.583 & -2.448 & 0.682 \\
\hline
\end{tabular}

Variables: peak ground reaction force (pGRF); time-to-peak ground reaction force (tpGRF); rate of force development (RFD). Units: Body weight (BW), Seconds (s). *Denotes $P<0.05$

and extraneous components that help create the turf construct could alter results. Results from this study are consistent with previous findings (Bennett et al., 2015; Brock et al., 2014; Gehring, Rott, Stapelfeldt, Gollhofer, 2007; Smith et al., 2004) when looking at GRF for various cleats and sport-specific movements. Results showed no differences in vertical pGRF between footwear conditions in this study. This is supported by Brock et al. (2014) who found no significant differences among peak vertical ground reaction forces and loading rates between natural and synthetic turf cleats, while values were significantly larger when performing a $90^{\circ}$ cut versus a $180^{\circ}$ cut. Brock et al. (2014) reported values of 5.0 body weight (BW), 5.0 BW, and 4.8 BW for peak vertical GRF in a synthetic turf cleat, natural turf cleat, 
and running shoe, respectively. Similarly, mediolateral GRF were consistent with 1.4 BW, 1.3 BW, and 1.3 BW, while time-to-peak GRF measured $0.050 \mathrm{~s}, 0.047 \mathrm{~s}$, and $0.048 \mathrm{~s}$ within the same footwear conditions. Values are consistent with, yet slightly higher than the current study; however, the protocol carried out by Brock et al. (2014) had participants complete a single jump followed by a $90^{\circ} \mathrm{SCM}$ immediately upon landing, potentially accounting for the discrepancies in GRF measurements and impact forces compared to straightline running.

Differences in RFD were not found between footwear conditions; however, this was expected due to its two calculating variables, force and time, not exhibiting significance. Normalized RFD values have shown to be nearly 103.0 $\mathrm{BW} / \mathrm{s}$ in running shoes, synthetic turf cleats, and natural turf cleats (Brock et al., 2014) and as low as $21.32 \mathrm{BW} / \mathrm{s}$ while wearing a six-studded soccer cleat (Smith et al., 2004). Results match closely with those of the latter study (Smith et al., 2004) taking into account the various phases of the SCM. Smith et al. (2004) reported a loading rate of 21.32 $\mathrm{BW} / \mathrm{s}$ and $26.09 \mathrm{BW} / \mathrm{s}$ for training shoes and soccer cleats, respectively; whereas the current study reports values of 15.75 $\mathrm{BW} / \mathrm{s}$ and $17.09 \mathrm{BW} / \mathrm{s}$. Utilizing a mechanical device to measure the coefficient of friction of various surfaces and comparing the forces from a $180^{\circ}$ turning movement, Dura et al. (1999) concluded that surfaces do not influence maximum GRF, impulse, or total time. However, more time was ultimately spent in the braking phase, similar to the current study, when the frictional force was higher between the cleat and playing surface, while less time was needed to propel the athlete in the desired direction (Durá et al., 1999). During a $\mathrm{SCM}$, a greater frictional force leads to an increase in joint torque; however, while an increase in torque may cause injuries at a joint, added time in the braking phase allows the knee to flex to a greater degree acting as a protective mechanism (Durá et al.,1999). This may indicate that athletes alter their movement based on the shoe-surface interaction.

Often critiqued, placing artificial turf over a force platform will not compromise data. Written in FIFA Quality Concept for Football Turf: Handbook of Test Methods (2009) and reported in McGhie et al. (2013), force platform data averaged a mean peak impact which was $98.7 \%$ $\pm 1.2 \%$ (range, $98.0-99.8 \%$ ) of the average recorded by a mechanical apparatus across all artificial turf meeting Fédération Internationale de Football Association (FIFA) standards. It should be noted that this study was limited to a small sample size and it did not control for the participants' approach/running speed and cutting angle to reflect natural on-field SCM mechanics of each participant. However, it has been shown that technique is more important than running speed or cutting angle in regards to preventing injury since it alters posture, muscle activation, and preparation time when it is controlled (Besier, Lloyd, Cochrane, \& Ackland, 2001). Future studies should consider the stresses placed on lower extremity joints during a SCM through a kinematic analysis to determine if cleated footwear designed for different sports alter force production. This, in combination with the current study, could poten- tially provide athletes information to select appropriate and desired footwear without compromising functional comfort for performance or injury risk.

\section{CONCLUSION}

To our knowledge, this is the first study to break down the SCM into two distinct phases and analyze how athletic cleats designed for different sports affect kinetic variables in a vertical and mediolateral direction. The SCM is one of many common techniques that allows an athlete to excel on the playing field. It is critical to understand the affect different footwear may have on vertical and mediolateral force generation to assist athletes, parents, and coaches to choose footwear that provides traction to perform the sport movement effectively. The current study suggests commonly worn cleated and non-cleated footwear produce similar GRFs, tpGRFs, and RFD during the braking and propulsion phase of a SCM. While all three types of footwear are providing traction, the similarities between kinetic variables indicate no one footwear analyzed provided specific performance advantages to an athlete in order to rapidly slow down or "brake" and accelerate during a SCM. Future research should examine various cleats with different stud variations to understand how the GRF affect kinematics at the lower extremity.

\section{ACKNOWLEDGEMENTS}

The authors would like to thank all of the participants for their time and efforts. The results of the present study do not constitute endorsement of any product and there are no conflicts of interests or affiliations with any of the manufacturers of equipment used.

\section{REFERENCES}

American College of Sports Medicine (ACSM). (2017). ACSM's guidelines for exercise testing and prescription $\left(10^{\text {th }} \mathrm{ed}\right.$.). Philadelphia, PA: Lippincott, Williams, \& Wilkins.

Bennett, H. J., Brock, E., Brosnan, J.T., Sorochan, J.C., \& Zhang, S. (2015). Effects of two football stud types on kneeand ankle kinetics of single-leg land-cut and $180^{\circ}$ cut movements on infilled synthetic turf. Journal of Applied Biomechanics, 31(5). https://doi.org/10.1123/jab.2014-0203

Besier, T. F., Lloyd, D.G., Cochrane, J.L., \& Ackland, T.R. (2001). External loading of the knee joint during running and cutting maneuvers. Medicine and Science in Sports and Exercise, 33(7), 1168-1175. doi: 10.1097/00005768200107000-00014

Brock, E., Zhang, S., Milner, C., Liu, X., Brosnan, J.T., \& Sorochan, J.C. (2014). Effects of two football studconfigurations on biomechanical characteristics of single-leg landing and cutting movements on infilled synthetic turf. Sports Biomechanics, 13(4), 362-379. doi: 10.1080/14763141.2014.965727

Cazás-Moreno, V. L., Gdovin, J.R., Williams, C.C., Allen, C.R., Fu, Y.-C., Brown, L.E., \& Garner, J.C. (2015). Influence of whole body vibration and specific warm-ups 
on force during an isometric mid-thigh pull. International Journal of Kinesiology and Sports Science, 3(4), 3139. doi: 10.7575/aiac.ijkss.v.3n.4p.31

Clarke, J. \& Carré, M. (2010). Improving the performance of soccer boots on artificial and natural soccer surfaces. Procedia Engineering, 2(2), 2775-2781. doi: 10.1016/j. proeng.2010.04.065

Driscoll, H., Kelley, J., Kirk, B., Koerger, H., \& Haake, S. (2015). Measurement of studded shoe-surface interaction metrics during in situ performance analysis. Sports Engineering, 18(2), 105-113. doi: 10.1007/s12283-014-0163-1

Durá, J. V., Hoyos, J., Martinez, A., \& Lozano, L. (1999). The influence of friction on sports surfaces in turning movements. Sports Engineering, 2, 97-102. doi: 10.1046/j.1460-2687.1999.00024.x

Dvorak, J. \& Junge, A. (2000). Football injuries and physical symptoms. A review of the literature. American Journal of Sports Medicine, 28(5), S3-9. doi: 10.1177/28.suppl_5.S-3

Fernandez, W. G., Yard, E.E., \& Comstock, R.D. (2007). Epidemiology of lower extremity injuries among US highschool athletes. Academic Emergency Medicine, 14(7), 641-645. doi: 10.1197/j.aem.2007.03.1354

Fédération Internationale de Football Association (FIFA). (2007). FIFA big count 2006: 270 million people active infootball. FIFA Communications Division, Information Services, 31. Available from: www.fifa.com

Gehring, D., Rott, F., Stapelfeldt, B., \& Gollhofer, A. (2007). Effect of soccer shoe cleats on knee joint loads. International Journal of Sports Medicine, 28(12), 1030-1034. doi: 10.1055/s-2007-965000

Haff, G. G., Ruben, R.P., Lider, J., Twine, C., \& Cormie, P. (2015). A comparison of methods for determining the rate of force development during isometric midthigh clean pulls. The Journal of Strength \& Conditioning Research, 29(2), 386-395. doi: 10.1519/JSC.0000000000000705

Havens, K. L. \& Sigward, S.M. (2015). Joint and segmental mechanics differ between cutting maneuvers in skilled athletes. Gait \& Posture, 41(1), 33-38. doi: 10.1016/j. gaitpost.2014.08.005

Iacovelli, J. N., Yang, J., Thomas, G., Wu, H., Schiltz, T., \& Foster, D.T. (2013). The effect of field condition and shoe type on lower extremity injuries in American football. British Journal of Sports Medicine, 47(12), 789793.doi: 10.1136/bjsports-2012-092113

Kent, R., Forman, J.L., Crandall, J., \& Lessley, D. (2015a). The mechanical interactions between an American football cleat and playing surfaces in-situ at loads and rates generated by elite athletes: Acomparison of playing surfaces. Sports Biomechanics, 14(1), 1-17. doi: 10.1080/14763141.2015.1024277

Kent, R., Forman, J.L., Lessley, D., \& Crandall, J. (2015b). The mechanics of American football cleats on natural grass and infill-type artificial playing surfaces with loads relevant to elite athletes. Sports Biomechanics, 14(2), 246- 257. doi: 10.1080/14763141.2015.1052749

McGhie, D. \& Ettema, G. (2013). Biomechanical analysis of surface-athlete impacts on third-generation artificial turf. The American Journal of Sports Medicine, 41(1), 177-185. doi: 10.1177/0363546512464697
McGovern, A., Dude, C., Munkley, D., Martin, T., Wallace, D., Feinn, R., Dione, D., \& Garbalosa, J.C. (2015). Lower limb kinematics of male and female soccer players during a self-selected cutting maneuver: Effects of prolonged activity. The Knee, 22(6), 510-516. Retrieved from https://spts.org

McLean, S. G., Neal, R.J., Myers, P.T., \& Walters, M.R. (1999). Knee joint kinematics during the sidestep cutting maneuver: Potential for injury in women. Medicine and Science in Sports and Exercise, 31(7), 959-968. doi: 10.1097/00005768-199907000-00007

McNitt, A., Middour, R. \& Waddington, D. (1997). Development and evaluation of a method to measure traction on turfgrass surfaces. Journal of Testing and Evaluation, 25(1), 99-107. Retrieved from www.astm.org

Meijer, K., Dethmers, J., Savelberg, H., Willems, P., \& Wijers, B. (2006). Biomechanical analysis of running on third generation artificial soccer turf. The Engineering of Sport 6, 29-34. doi: 10.1007/978-0-387-46051-2_6

National Federation of State High School Associations. (2017). 2016-17 high school athletics participation survey. Available at: http://www.nfhs.org/ParticipationStatistics/PDF/2016-17_Participation_Survey_Results.pdf

Nigg, B. M. (1989). Surface-related injuries in soccer. Sports Medicine, 8(1), 56-62. doi: 10.2165/00007256198908010-00006

Powell, J. W. \& Barber-Foss, K.D. (1999). Injury patterns in selected high school sports: A review of the 1995-1997 seasons. Journal of Athletic Training, 34(3), 277. Retrieved from/www.nata.org

Queen, R. M., Charnock, B.L., Garrett, W.E., Hardaker, W.M., Sims, E.L., \& Moorman, C.T. (2008). A comparison ofcleat types during two football-specific tasks on FieldTurf. British Journal of Sports Medicine, 42(4), 278-284. doi: 10.1136/bjsm.2007.042507

Saggini, R. \& Vecchiet, L. (1994). The foot-ground reaction in the male and female soccer players. Proceedings of the International Society of Biomechanics in Sports XII, 213215. Retrieved from https://isbweb.org/resources/journals

Smith, N., Dyson, R., \& Janaway, L. (2004). Ground reaction force measures when running in soccer boots and soccer training shoes on a natural turf surface. Sports Engineering, 7(3), 159-167. doi: 10.1007/BF02844054

SportsTurf Managers Association (STMA). (2008). A guide to synthetic and natural turfgrass for sports fields: Selection, construction and maintenance ( $2^{\text {nd }}$ ed.). Lawrence, KS: Author.

Sterzing, T. (2016). Soccer boots and playing surfaces. Soccer Science, 339, 179-202. doi: 10.1177/0363546507300257.

Vanrenterghem, J., Venables, E., Pataky, T., \& Robinson, M.A. (2012). The effect of running speed on knee mechanical loading in females during side cutting. Journal of Biomechanics, 45(14), 2444-2449. doi: 10.1016/j. jbiomech.2012.06.029

Verhelst, R., Malcolm, P., Verleysen, P., Degrieck, J., De Clercq, D., \& Philippaerts, R. (2008). Ground reaction force of a drop jump on different kinds of artificial turf. In T. Reilly \& F. Korkusuz (Eds.), Science and football VI: The proceedings of the sixth world congress on science and football (pp. 70 - 75). New York City, NY: Routledge. 